Original Research

\title{
Soil Aggregate Response to Three Freeze-Thaw Methods in a Northeastern China Mollisol
}

\author{
Shuai Chen ${ }^{1-3}$, C. Lee Burras ${ }^{2}$, Xingyi Zhang** \\ ${ }^{1}$ Key laboratory of Mollisols Agroecology, Northeast Institute of Geography and Agroecology, \\ Chinese Academy of Sciences, Harbin, China \\ ${ }^{2}$ Department of Agronomy, Iowa State University, Ames, Iowa, USA \\ ${ }^{3}$ University of Chinese Academy of Sciences, Beijing, China
}

Received: 8 March 2018

Accepted: 25 October 2018

\begin{abstract}
Freeze-thaw (FT) cycles occur annually in soils of mesic and frigid temperature regimes. FT has profound impacts on soil aggregates yet is often difficult to document in field settings. As a result, laboratory-based FT experiments are widely used, albeit with their own limitations. Both laboratory and field-based research indicates that aggregate properties vary with rates of freezing and thawing as well as the number and amplitudes of FT cycles. In this study, we introduce a continuous freezing-to-thawing-to-freezing technique (i.e., "VTR") and compare it to a commonly used discrete freeze-then-thaw-then-freeze method (i.e., "RTCR") and compare both results to natural seasonal changes. Our study soil is the A horizon of the major cropped mollisol in northeastern China. We examined it under natural field soil moisture conditions as well as two controlled soil moisture contents in the laboratory. Both RTCR and VTR show a decrease in large $(>1 \mathrm{~mm})$ aggregate content and a corresponding increase in medium $(0.5$ to $0.2 \mathrm{~mm})$ aggregates $(\mathrm{P}>0.05)$ that is proportional to the number of FT cycles and soil moisture content. Wet aggregate stability (WAS) increased $(\mathrm{P}<0.05)$ over the time of the experiment with each method. RTCR data showed an interaction between FT cycles and soil water content. VTR was better, although certainly not with better matched field results than RTCR, which we attribute its FT cycles being matched to anactual field. These results confirm the dependability and authenticity of the VTR technique.
\end{abstract}

Keywords: simulation, freeze-thaw cycles, water contents, soil aggregate stability

\section{Introduction}

Seasonal freezing-thawing events frequently occur in mid-high and high altitudes and latitudes. Freeze-thaw (FT) cycles have great impact on soil physical, chemical

*e-mail: zhangxy@iga.ac.cn and biological properties during the late winter and early spring [1-6]. Essentially, the degree of this effect is controlled by the inherent properties of FT cycles (rate, temperature and duration period) and soil (moisture content, organic matter content, microbial biomass, bulk density, etc.) [7-9]. Numerous studies have tested the impact of FT cycles on soil aggregate stability. The results showed inconsistencies. Some studies have indicated that soil aggregate stability decreases with an 
increasing number of FT cycles [9-10]; whereas in others there were reverse results [11]. In other words, freezethaw cycles can have either positive or negative effects on soil aggregates [12-15].

Most of the cited studies used - at least in part - the traditional discrete FT method, which can be named "repeated temperature cycle regime" (RTCR) treatments, to simulate FT cycles. RTCR uses the constant temperature of freezing and thawing, as well as a constant number and frequency of cycles on small amounts of homogenized in-situ soils [9, 14]. RTCR is designed on the principle that the laboratory application of a well-defined and widely-used method will identify the controlling soil properties and field conditions that result in more or less soil aggregate stability.

The biggest challenge with RTCR is that it only partially simulates field conditions. The very "constancy" of FT patterns in the RTCR can limit its applicability to actual field conditions because the length and frequency of FT cycles in the field varies in any given winter as well as winter-to-winter [16]. This challenge seems especially pronounced when the RTCR uses short FT periods (e.g., 1 or 2 days or even 1 or 2 weeks) [17]. In order to capitalize upon the strength of RTCR in giving replicable results under controlled experimental conditions, we developed a continuous FT method, which can be named "variable temperature regime" (VTR) treatment. It combines continuously freezing and thawing regimes with large soil volumes in order to better simulate the natural FT cycles of northern China. The objectives of this study were (a) to develop a variable temperature regime (VTR) treatment for FT for the upper $15 \mathrm{~cm}$ of soil, and (b) to evaluate the effect of different FT types on the soil aggregate size distribution and soil wet aggregate stability (WAS).

\section{Material and Methods}

\section{Site Description}

The study area is located close to the city of Hailun in the center of the mollisol zone in northeastern China $\left(47^{\circ} 21^{\prime} \mathrm{N}, 126^{\circ} 50^{\prime} \mathrm{E}\right)$. The region is a temperate continental monsoon climate (cold and very dry in winter, hot and rainy in summer). Average annual precipitation is $530 \mathrm{~mm}$, with $65 \%$ of rainfall occurring from June to August. Annual sunshine is about 2600-2800 h. Annual average available accumulated temperature $\left(\geq 10^{\circ} \mathrm{C}\right)$ is $2450^{\circ} \mathrm{C}$ and total annual solar radiation is $4600 \mathrm{MJ} \mathrm{m}^{-2}$ [18].

Average annual temperature is $1.5^{\circ} \mathrm{C}$ with an extreme minimum temperature of $-39.5^{\circ} \mathrm{C}$ and an extreme maximum temperature of $+37^{\circ} \mathrm{C}$ (average for

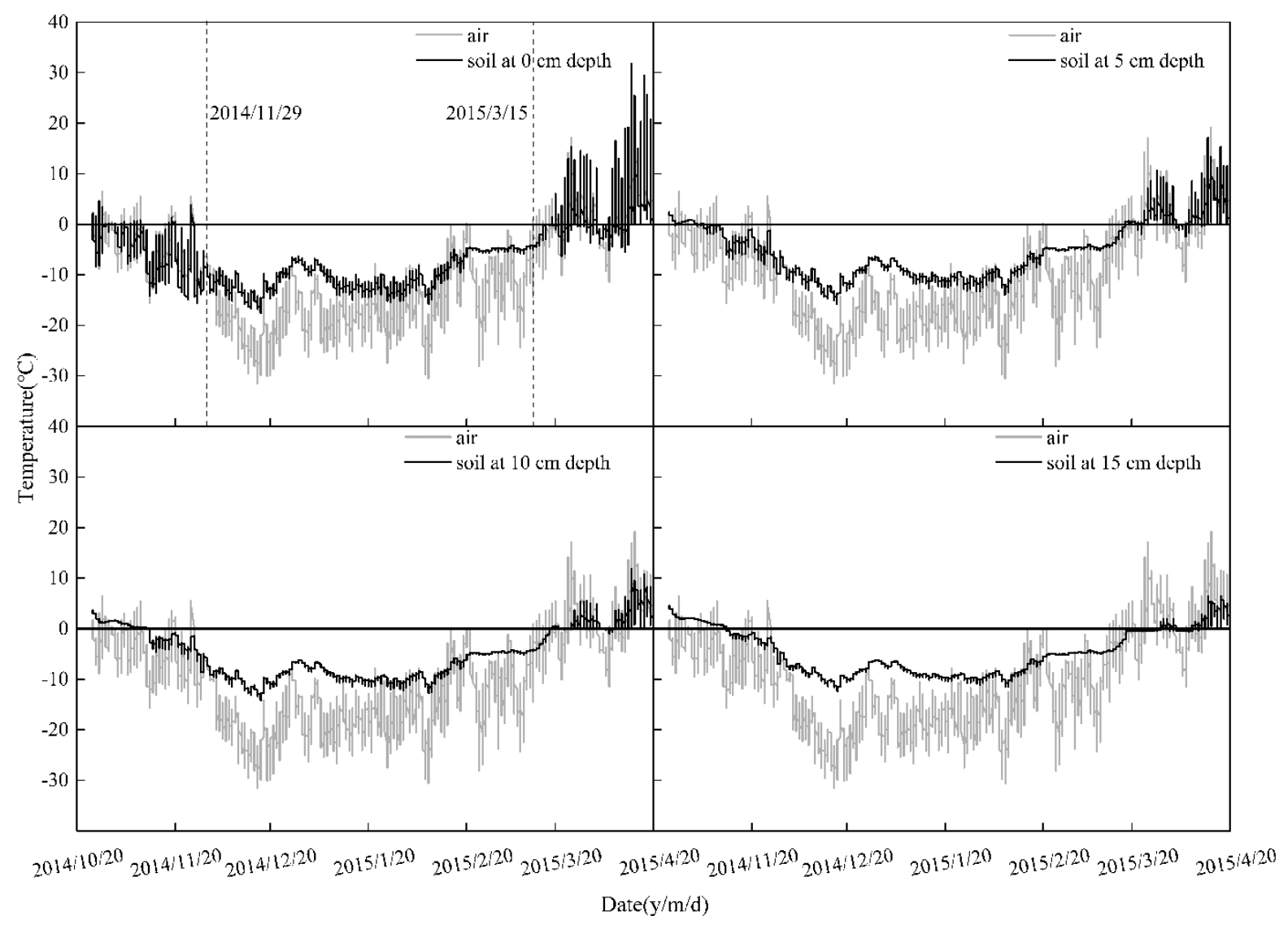

Fig. 1. Hourly field air and soil temperatures in the NEIGAE mollisol plot in northeastern China; soil temperatures given at 0, 5, 10 and $15 \mathrm{~cm}$ depths. 
Table 1. Basic physical and chemical properties of the experimental Mollisol $(0-20 \mathrm{~cm})$.

\begin{tabular}{|c|c|c|c|c|c|}
\hline \multicolumn{3}{|c|}{ Soil texture (\%) } & \multirow{2}{*}{ Bulk density $\left(\mathrm{g} \mathrm{cm}^{-3}\right)$} & SOM $\left(\mathrm{g} \mathrm{kg}^{-1}\right)$ & $\mathrm{pH}\left(\mathrm{H}_{2} \mathrm{O}\right)$ \\
\cline { 1 - 2 } Sand & Silt & Clay & 1.12 & 44.1 & 6.6 \\
\hline 25.5 & 33.7 & 40.8 & & \\
\hline
\end{tabular}

2004-2011) [19]. From late November to early March, the temperature of the soil surface horizon $(0-15 \mathrm{~cm})$ remains below $0^{\circ} \mathrm{C}$, and the soil surface layer as well as the region's water bodies are frozen permanently. Freezing conditions in this region generally begin in late October, while thawing normally predominates in late March (Fig. 1), during which the temperature of the soil surface horizon $(0-15 \mathrm{~cm})$ fluctuates around $0^{\circ} \mathrm{C}$ with the soil progressively thawing more and more with each passing day and re-freezes less and less with each subsequent night. These conditions result in two periods of seasonal FT for the mollisols of NE China: (a) winter freezing period and (b) spring thawing period. We chose the air temperature fluctuations from Oct. 26 to Nov. 29 and from Mar.15 to Apr. 20 as our VTR settings.

The study soil is a loess-derived fine, mixed, superactive, Oxyaquic Haplocryoll. It has light clay texture, slightly acidic reaction and $4.4 \%$ soil organic matter (SOM) (Table 1) [20].

\section{Experimental Design}

The experiment was conducted in the Key Laboratory of Mollisols Agroecology, Northeast Institute of Geography and Agroecology, Chinese Academy of Sciences. Soil samples were collected from the cultivated layer $(0-15 \mathrm{~cm})$ in late October 2014, prior to the first soil freezing event, and air-dried at room temperature, crushed and sieved through a $10 \mathrm{~mm}$ mesh before experiment. In order to analyze the effect of seasonal FT cycle on soil aggregates, we collected soil again from the cultivated layer $(0-15 \mathrm{~cm})$ in late April 2015, after the last soil thawing event.

Fig. 2 shows a flow diagram of the comparison of both methods we used (RTCR and VTR).

VTR soil samples were put into 78 incubation vessels $(13 \mathrm{~cm}$ width* $8 \mathrm{~cm}$ length* $15 \mathrm{~cm}$ height* $1.5 \mathrm{~cm}$ thickness) made of polyolefin foam with good

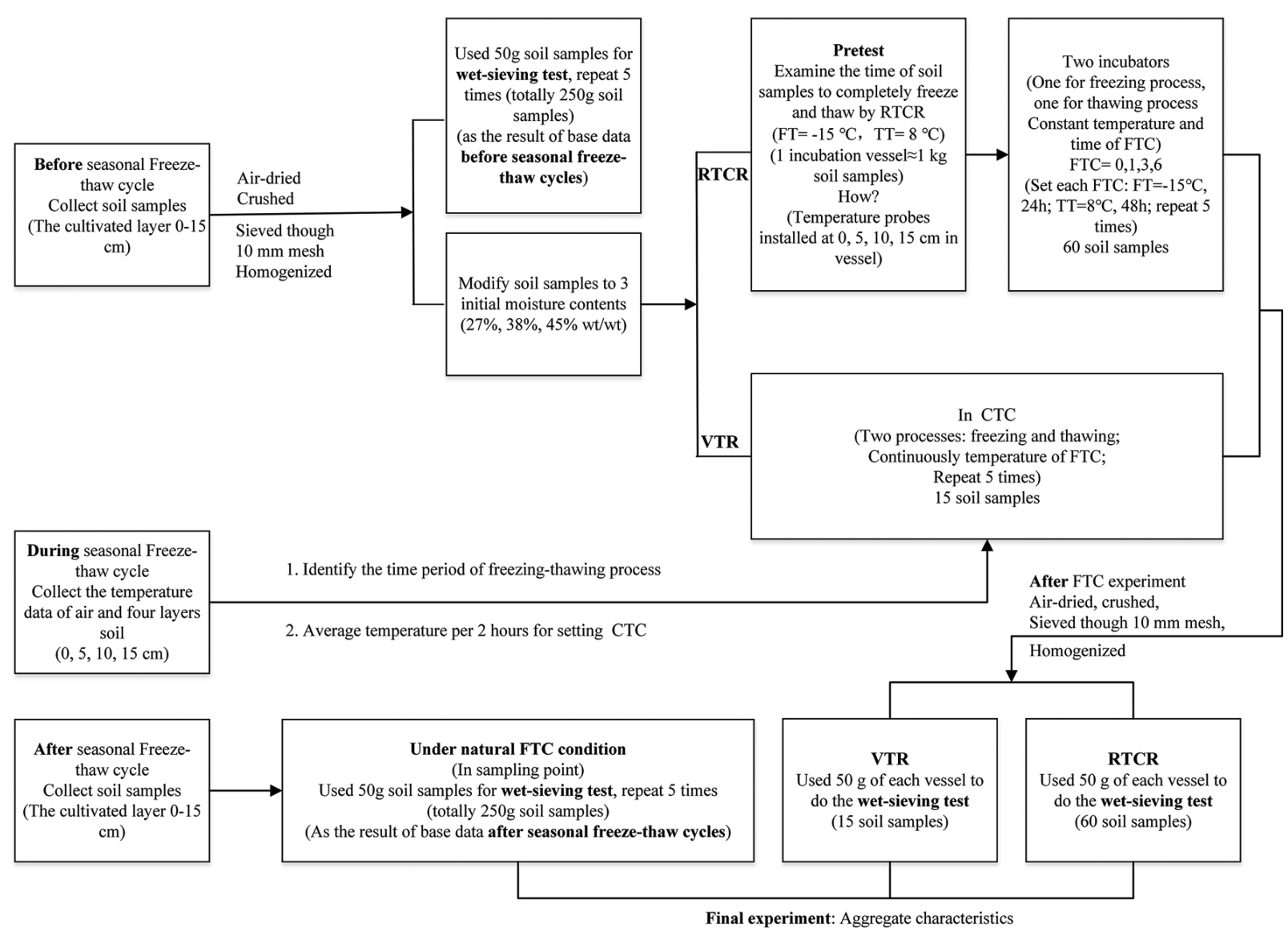

Fig. 2. Flow diagram comparing measuring soil aggregate stability using the repeated temperature cycle regime (RTCR) treatment, variable temperature regime (VTR) treatment and natural freeze-thaw cycles. 
adiabaticity (thermal conductivity $=0.031 \mathrm{~W} \mathrm{~m}^{-1} \mathrm{~K}^{-1}$ ). The incubation vessels have well insulated sides and bottom. The design insures the soil freeze-thaw process is driven by the interaction between chamber air temperature and the soil surface. This set-up simulates the natural freezing process along soil depth. The large well-insulated incubation vessels specifically prevent unreal large temperature fluctuations during FT cycles. With rapid freezing, the physical disruption of soil aggregates is minimized.

Using the nHVSW (new high vacuum slow wetting) method [20], soil samples were modified to 3 experimental moisture contents: $\mathrm{W} 1=27 \%(\mathrm{~g} / \mathrm{g})$, which represents near droughty field conditions; W2 $=38 \%$ $(\mathrm{g} / \mathrm{g})$, which is field capacity; and $\mathrm{W} 3=45 \%(\mathrm{~g} / \mathrm{g})$, which is near saturation. These moisture contents resulted in soil water being primarily in micropores (W1), in both micropores and mesopores (W2) and filling nearly pores including macropores (W3).

As previously indicated, two methods (RTCR, VTR) were used to induce freezing and thawing. RTCR had constant temperatures of freezing and thawing, constant number and frequency of FT cycles while VTR was set to the air temperature at the field site during the FT period (Fig. 2).

For the RTCR technique, 60 soil samples were placed in a temperature-controlled deep-freezer set at $-15^{\circ} \mathrm{C}$ for freezing cycles and $8^{\circ} \mathrm{C}$ for thawing cycles. We carried out a pilot test before the actual experiment to examine the time it took for the soil samples to completely freeze and thaw. The temperature of each soil sample layer was detected directly by using a temperature recorder having 4 temperature probes installed in each soil layer (surface, 5, 10 and $15 \mathrm{~cm}$ ). We found that each soil sample with different water contents froze completely at $-15^{\circ} \mathrm{C}$ after $24 \mathrm{~h}$, and then thawed completely under the conditions of $8^{\circ} \mathrm{C}$ after $48 \mathrm{~h}$. Thus freezing and thawing time was set $24 \mathrm{~h}$ and $48 \mathrm{~h}$, respectively. This freezing and thawing procedure was repeated for $0,1,3$ and 6 cycles.
The VTR technique introduced in this study was conducted using the previously described soil incubation vessels that were placed in a controlled temperature chamber (CTC). The CTC model we used (LRH-150 CA, Shanghai Bluepard Instruments Co. Ltd., China) can be programmed for continuous temperature fluccuations. Using temperature probes and the field-based freezing and thawing data described in the following paragraph, we set 2 hours as a unit of the experiment within that time period consisting of two stages. The first 30 minutes was a buffering stage. The final 90 minutes was the experimental stage.

Before we started the laboratory experiment, we collected in situ air and soil temperature $(0-15 \mathrm{~cm})$ from the early fall to late spring. Soil temperature was measured at four depths: surface, $5,10,15 \mathrm{~cm}$ in the field. These were used to identify the proper temperatures and duration of FT cycles in the CTC (Fig. 1). More specifically, we collated those field temperature data to determine the average temperature for each 2-hour experimental unit of the CTC. As already described, the first 30-minute stage was when the chamber temperature was raised or lowered to mimic the appropriate field conditions. The following 90 minute stage was kept at a constant temperature. As with the actual fluctuation of temperature in the field, 12 units were set for one day in CTC and another 12 units were set in the following day (Fig. 3). The temperature in CTC was observed during the FT cycles experiment in VTR (Fig. 4). Although the temperature fluctuation at CTC was not perfectly matched with those at the field site, VTR did provide consecutive temperature fluctuations akin to diurnal fluctuations in the field.

After the freezing and thawing treatment, soil samples were air-dried and then wet-sieved. The wetsieving apparatus by Sun et al. (2014) [20] was used on all samples, and each treatment was replicated five times. Fifty g soil samples (air-dried passed through

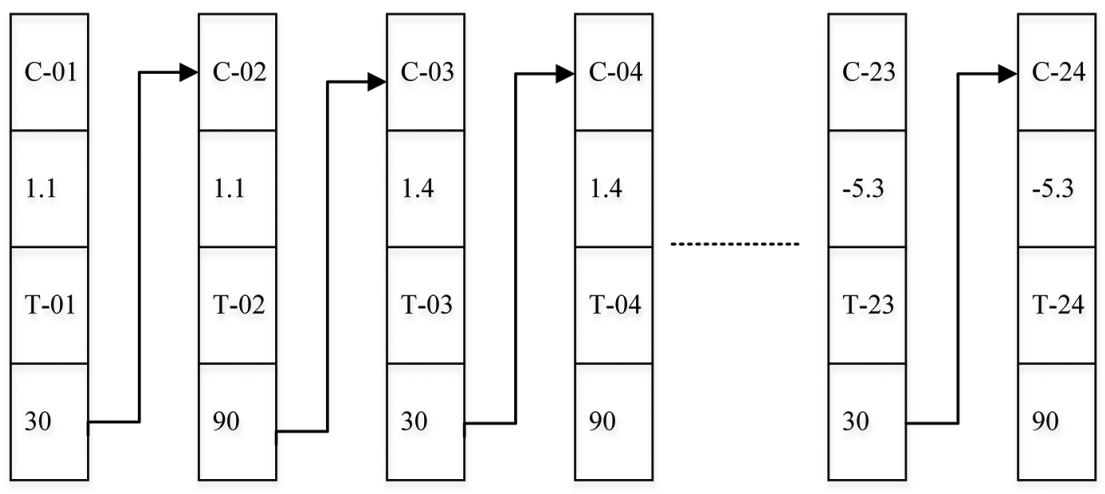

Fig. 3. Demonstration of settings for the rapid temperature experiment chamber as used in the variable temperature regime (VTR) treatment for measuring mollisol aggregate stability in northeastern China (C-01: the first section desired temperature, T-01: the time from current measured value temperature to the first section desired temperature, $\mathrm{C}-02$ : the first section desired temperature, T-02: the time of keeping the constant desired temperature). 


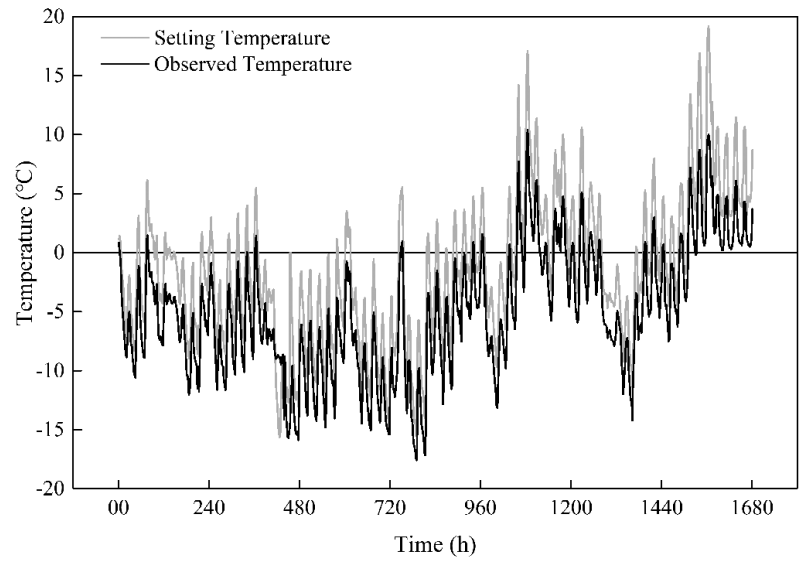

Fig. 4. Comparison of rapid temperature experiment chamber setting temperature and actual soil ("observed") temperature in a large mollisol sample from northestern China.

$10 \mathrm{~mm}$ sieve) were placed on the top of a nest of four sieves $(5,2,0.5,0.25 \mathrm{~mm})$ and submerged in distilled water for $10 \mathrm{~min}$. Soil was then vertically sieved by the apparatus with $3 \mathrm{~cm}$ displacement and a rate of 30 cycles per minute for $2 \mathrm{~min}$. The resistant soil on each sieve and the unstable $(<0.25 \mathrm{~mm})$ aggregates below the bottom sieve were collected by transferring them into beakers. These soil samples were dried in an oven at $50^{\circ} \mathrm{C}$ for $48 \mathrm{~h}$ and weighed. This data was used to determine the percentage of each aggregate size as well as the overall WAS content.

\section{Statistical Analysis}

Statistical analysis was done using SPSS 16.0 software (SPSS 16.0 for windows). The general linear model (GLM) procedure was performed to analyze treatment effects, including different FT treatments, water contents, and interactions between FT treatments and water contents. Tukey's multiple comparison test was used for comparing means. The GLM procedure and Tukey's were used to test whether the differences between aggregate size distribution and WAS measured with the two methods differed significantly for different FT treatments and water contents.

\section{Results}

In order to validate the statistical validity of this experiment, an initial GLM test was conducted (Table 2). All treatments and their interactions were significant at $\mathrm{P}=0.001$ for all aggregate sizes and WAS (Table 2).

\section{Water Content Effect}

Water content of soil samples influenced aggregate size distribution and WAS with different FT treatments (Table 3). The value of WAS decreased with increasing water content following freezing and thawing with both RTCR and VTR. After six FT cycles in RTCR, the WAS content significantly $(\mathrm{P}<0.05)$ decreased by $7.69 \%, 4.19 \%$ and $2.45 \%$ compared to the initial aggregate stability under $27 \%, 38 \%$ and $45 \%$ water contents, respectively. The proportion of soil aggregates significantly increased in the $0.25-1 \mathrm{~mm}$ fraction, but decreased in the other aggregate sizes $(1-10 \mathrm{~mm}$ and < $0.25 \mathrm{~mm}$ ) for $27 \%$ and $45 \%$ water contents. However, the percentage of soil aggregates significantly increased in the $0.5-2 \mathrm{~mm}$ fraction for $38 \%$ water content after FT treatment. The proportion of soil mass in aggregates $<0.25 \mathrm{~mm}$ was the largest fraction of the soil, followed sequentially by the $0.5-1,0.25-0.5,1-2$ and $2-10 \mathrm{~mm}$ fractions at all water contents after FT cycles. The value of WAS under different water contents increased by $3.27 \%$ to $9.25 \%$ after VTR treatment (Table 3). The smallest percentage increase was for $27 \%$ water content, and the greatest increase was 38\% water content. The largest percentage of aggregates were in the $0.5-2,0.25-0.5$ and $0.5-1 \mathrm{~mm}$ sizes for $27 \%, 38 \%$ and $45 \%$ water contents, respectively, before the beginning of FT. Aggregate size of $0.5-1 \mathrm{~mm}$ became the second largest percentage of aggregate size distribution after FT under all water contents (Table 3).

\section{Freeze-Thaw Cycles Effect}

FT impact on soil aggregate size distribution and WAS was significant $(\mathrm{P}<0.05)$ under all FT conditions (Table 3). The initial WAS (0 freeze-thaw cycle) of soil at $27 \%$ and $45 \%$ water contents was significantly $(\mathrm{P}<0.05)$ higher than soil at $38 \%$ water content.

Table 2. Probability values from the GLM test evaluating the effect of water contents (W), freeze-thaw treatments (FTT) and the W*FTT interaction on aggregate size distribution and wet aggregate stability (WAS) of the experimental mollisol $(\mathrm{n}=75)$.

\begin{tabular}{|c|c|c|c|c|c|c|}
\hline \multirow{2}{*}{ Treatments } & \multicolumn{7}{|c|}{ Aggregate size distribution (mm) } & \multirow{2}{*}{ WAS (\%) } \\
\cline { 2 - 6 } & $2-10$ & $1-2$ & $0.5-1$ & $0.25-0.5$ & $<0.25$ & $<0.001$ \\
\hline W & $<0.001$ & $<0.001$ & $<0.001$ & $<0.001$ & $<0.001$ & $<0.001$ \\
\hline FTT & $<0.001$ & $<0.001$ & $<0.001$ & $<0.001$ & $<0.001$ & $<0.001$ \\
\hline W * FTT & $<0.001$ & $<0.001$ & $<0.001$ & $<0.001$ & $<0.001$ & $<0.001$ \\
\hline
\end{tabular}

FTT=freeze-thaw treatments (FTC-0, FTC-1, FTC-3, FTC-6 and VTR) 
Table 3. Aggregate size distribution $\left(\mathrm{g} 100 \mathrm{~g}^{-1}\right)$ and wet aggregate stability (WAS) for the mollisol of different water contents (W) and freeze-thaw treatments $(\mathrm{FTT})(\mathrm{n}=75)$.

\begin{tabular}{|c|c|c|c|c|c|c|c|}
\hline \multirow{2}{*}{ W } & \multirow{2}{*}{ FTT } & \multicolumn{5}{|c|}{ Aggregate size distribution (mm) } & \multirow{2}{*}{ WAS $(\%)$} \\
\hline & & $2-10$ & $1-2$ & $0.5-1$ & $0.25-0.5$ & $<0.25$ & \\
\hline \multirow{5}{*}{$27 \%$} & FTC-0 & $13.26 \mathrm{a}$ & $17.17 \mathrm{a}$ & $19.20 \mathrm{~h}$ & $13.78 \mathrm{f}$ & $36.59 \mathrm{efg}$ & $63.41 \mathrm{def}$ \\
\hline & FTC-1 & $9.34 \mathrm{~cd}$ & $12.44 \mathrm{def}$ & $21.42 \mathrm{fg}$ & $18.41 \mathrm{de}$ & 38.39def & $61.61 \mathrm{efg}$ \\
\hline & FTC-3 & $5.02 \mathrm{fgh}$ & $11.49 \mathrm{ef}$ & $22.54 \mathrm{ef}$ & $20.21 \mathrm{bcd}$ & $40.74 \mathrm{~cd}$ & $59.26 \mathrm{gh}$ \\
\hline & FTC-6 & $10.91 b$ & $16.25 \mathrm{ab}$ & $25.84 \mathrm{bc}$ & $18.10 \mathrm{e}$ & $28.90 \mathrm{i}$ & $71.10 \mathrm{a}$ \\
\hline & VTR & $13.48 \mathrm{a}$ & $17.31 \mathrm{a}$ & $24.21 \mathrm{cde}$ & $17.66 \mathrm{e}$ & $27.34 \mathrm{i}$ & $72.66 \mathrm{a}$ \\
\hline \multirow{5}{*}{$38 \%$} & FTC-0 & 7.80de & $11.35 \mathrm{fg}$ & $16.74 \mathrm{i}$ & $20.91 b c$ & $43.20 \mathrm{bc}$ & $56.80 \mathrm{hi}$ \\
\hline & FTC-1 & 3.49hi & $9.77 \mathrm{gh}$ & $22.85 \mathrm{ef}$ & $18.15 \mathrm{e}$ & $45.74 \mathrm{ab}$ & $54.26 \mathrm{ij}$ \\
\hline & FTC-3 & 3.71hi & $9.22 \mathrm{~h}$ & $21.91 \mathrm{fg}$ & $18.52 \mathrm{de}$ & $46.64 a$ & $53.36 \mathrm{j}$ \\
\hline & FTC-6 & $4.41 \mathrm{gh}$ & 12.34def & $26.26 \mathrm{ab}$ & $17.98 \mathrm{e}$ & 39.01de & $60.99 \mathrm{fg}$ \\
\hline & VTR & $6.39 \mathrm{ef}$ & $16.35 \mathrm{ab}$ & $23.02 \mathrm{def}$ & $19.05 \mathrm{de}$ & 35.19ghi & $64.81 \mathrm{bcd}$ \\
\hline \multirow{5}{*}{$45 \%$} & FTC-0 & $10.20 b c$ & $16.25 \mathrm{ab}$ & $20.43 \mathrm{gh}$ & $17.60 \mathrm{e}$ & $35.52 \mathrm{fgh}$ & $64.48 \mathrm{cde}$ \\
\hline & FTC-1 & $2.80 \mathrm{i}$ & $8.41 \mathrm{~h}$ & $21.90 \mathrm{fg}$ & $24.23 \mathrm{a}$ & $42.66 \mathrm{bc}$ & 57.34hi \\
\hline & FTC-3 & $5.89 \mathrm{fg}$ & $13.17 \mathrm{cde}$ & $25.00 \mathrm{bcd}$ & 19.11cde & $36.83 \mathrm{efg}$ & $63.17 \mathrm{def}$ \\
\hline & FTC-6 & $5.40 \mathrm{fg}$ & $14.85 \mathrm{bc}$ & $27.91 \mathrm{a}$ & $18.77 \mathrm{de}$ & $33.07 \mathrm{hi}$ & $66.93 \mathrm{bc}$ \\
\hline & VTR & $6.16 \mathrm{f}$ & $13.84 \mathrm{~cd}$ & $26.50 \mathrm{ab}$ & $21.25 \mathrm{~b}$ & $32.25 \mathrm{~h}$ & $67.75 b$ \\
\hline
\end{tabular}

FTC $=$ number of freeze-thaw cycles, VTR $=$ continuous freeze-thaw method.

Means in columns without common lower case letter (a-j) differ significantly at $\mathrm{P}<0.05$.

More specifically, our data show that the content of large aggregates decreased after 1, 3 and 6 FT cycles regardless of antecedent water contents. At the same time, small aggregate sizes decreased significantly $(\mathrm{P}<0.05)$ only after 3 to 6 FT cycles, while the content of $0.5-1 \mathrm{~mm}$ aggregates increased significantly $(\mathrm{P}<0.05)$ during the FT cycles. After the first FT cycle in the RTCR method, the value of WAS significantly decreased in soils at $45 \%$ water content $(\mathrm{P}<0.05)$. For the samples with $27 \%$ and $38 \%$ water contents, significant $(\mathrm{P}<0.05)$ decrease in WAS occurred after 3 FT cycles. Compared with the samples at 0 cycle, the values of WAS for all samples were significant $(\mathrm{P}<0.05)$ - increasing after 6 FT cycles with the change in contents being $7.69 \%$, $4.19 \%$ and $2.45 \%$ under $27 \%, 38 \%$ and $45 \%$ water contents, respectively. Table 3 also showed the same change trend for aggregate size distribution after 1 FT cycle. The two large particle size groups (2-10 and 1-2 $\mathrm{mm}$ ) were decreased and the small particle size group $(<0.25 \mathrm{~mm})$ was increased in the RTCR treatment. Moreover, aggregates with large diameter $(>0.5$ $\mathrm{mm})$ were increased and others with small diameter $(<0.5 \mathrm{~mm})$ were decreased after 6 FT cycles (except for the $2-10 \mathrm{~mm}$ fraction in $45 \%$ water content). The largest and smallest values of WAS were found after 6 and 3 cycles, respectively (expect for the smallest WAS value at $45 \%$ water content). The VTR treatment impact on soil aggregate size distribution and WAS were similar with RTCR treatment after 6 FT cycles under the same water content (Table 3).

\section{Seasonal Freeze-Thaw Effect}

Under natural conditions, soil aggregate size distribution and WAS in situ were also affected significantly $(\mathrm{P}<0.05)$ by seasonal freezing-thawing cycles (Table 4). Soil aggregates of medium particle size group $(0.5-2 \mathrm{~mm})$ significantly $(\mathrm{P}<0.05)$ increased, while other particle size groups $(2-10$ and $<0.5 \mathrm{~mm})$ significantly $(\mathrm{P}<0.05)$ decreased after seasonal freezingthawing. The value of WAS increased $7.64 \%$ under natural conditions after seasonal freezing and thawing.

\section{Discussion}

Both aggregate size distribution and WAS in this study were affected significantly after freezing and thawing of soil. The results are similar to the observations of Wang et al. (2012) [9], which stated that the greatest loss of aggregates during FT cycles occurred within the largest aggregate. $\mathrm{Li}$ and Fan (2014) [14] explained the effect of soil water on aggregate size distribution and stability, which is due to the crushing effect or freezing expansion combined with a reorganization of the soil aggregate. When soil 
water becomes ice, the volume will expand and create a crushing effect. At the same time, the internal gas of the aggregate will shrink by cooling after freezing, which increases the subsequent effect. The crushing effect is more pronounced than reconstruction for the largest size aggregate, which results in a net loss of large aggregates.

Our results suggest that WAS decreased with increasing water contents after freezing and thawing. This result was supported by the research of $\mathrm{Li}$ and Fan (2014) [14], which observed that soil cohesion decreased with an increase in water contents. However, our result seems to be contrary to the report of Sun and Lu (2014) [21]. Previous researchers have indicated that the rewetting soil has lower aggregate stability than airdried soil [22-23]. Air drying can increase mechanical resistance to detachment and aggregate breakdown, while rewetting enhances the breakdown of soil aggregates by pressurizing entrapped air [24-27]. Studies conducted by Marquez et al. (2004) [28] also showed that wetting can affect soil cohesion, which normally caused larger aggregates to break apart, thereby increasing the percentage of smaller aggregates. After water moves into small intra-aggregate pores, pore air is trapped and then compressed, which causes aggregate breakdown and slaking [29-31]. This is likely the explanation as to why our soil samples at $27 \%$ (pores contain both air and water but more contain air than water) were as stable as they were. The crushing effect increased when water content increased from $27 \%$ to $38 \%$, but decreased after that point because at the highest water contents $(45 \%)$ the volume of air entrapped is very small. This results in lowered compressive force to act on the aggregates. This interpretation was in accordance with the result of Vermang et al. (2009) [24] and Liu et al. (2011) [31].

We observed that the number of FT cycles had no consistent effect on WAS and aggregate size distribution. After one FT cycle in the RTCR method, the value of WAS was lower than before freezing. This result seems to be contrary to the reports of Lehrsch et al. (1991) [32] and Kreyling et al. (2010) [33], who reported that freezing and thawing usually increased stability with the first FT cycle. However, after six FT cycles in the RTCR method the value of WAS increased significantly compared with three cycles of FT. This result was similar to the research of Oztas and Fayetorbay (2003) [34]. We found that a decreased percentage of aggregates occurred in the large aggregate size $(>1 \mathrm{~mm})$ after each FT cycle. This indicated that FT cycles can reduce large aggregate size fractions, while the effect of small aggregate size fractions varies with different FT cycles. Li and Fan (2014) [14] concluded that changes in aggregate size fractions with variable FT cycles are the result of the interaction between soil shrinking and expanding forces relative to the space between aggregates.

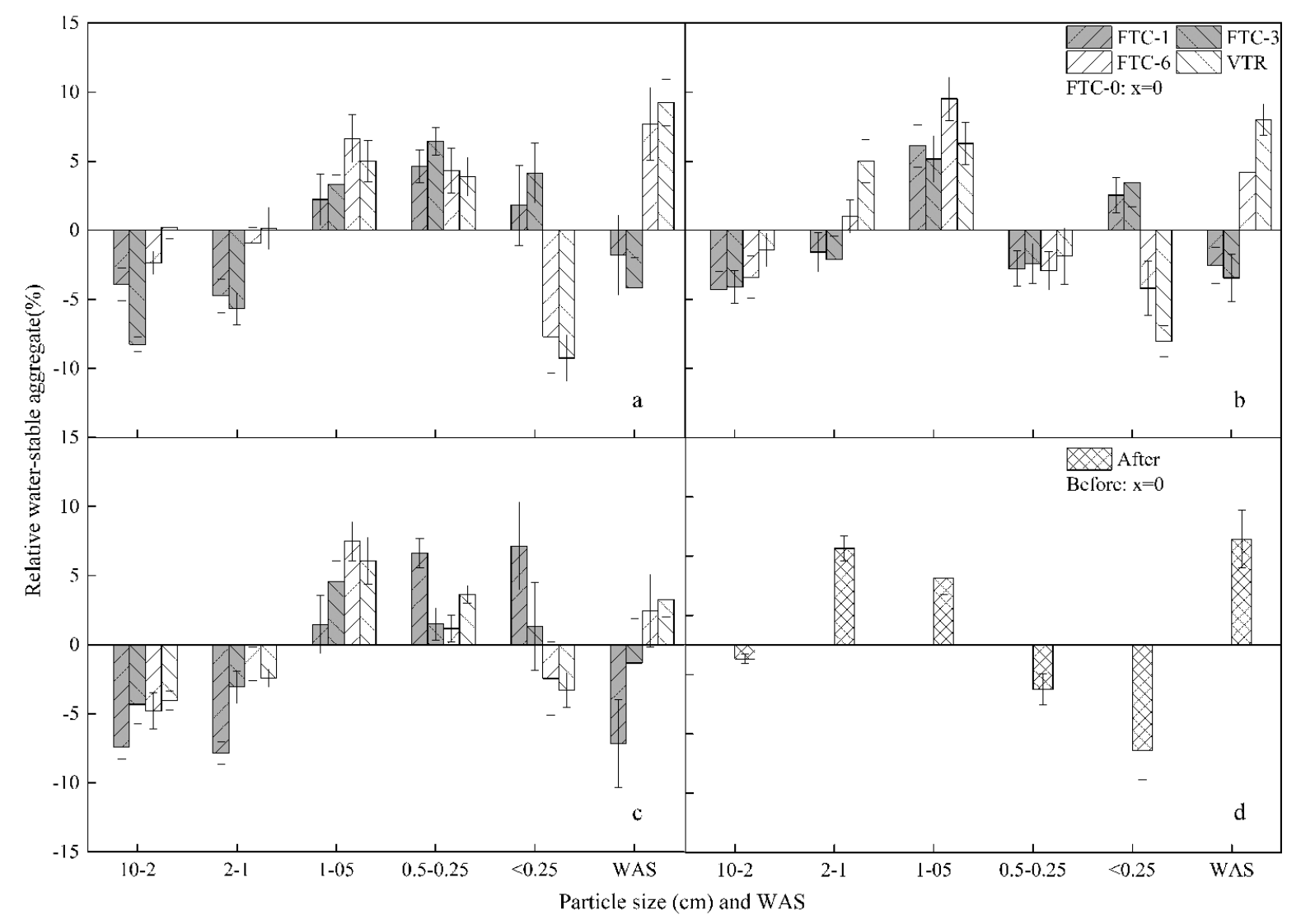

Fig. 5. Effects of different water contents (W) and freeze-thaw treatments (FTT) on soil aggregation in a mollisol from northeasterb China; data presented includes water stable aggregates (\%) and wet aggregate stability (WAS). 
Table 4. Aggregate size distribution ( $\mathrm{g} 100 \mathrm{~g}^{-1}$ ) and wet aggregate stability (WAS) for field experiment data of the soil before the freezing event and after the thawing event $(n=10)$.

\begin{tabular}{|c|c|c|c|c|c|c|}
\hline \multirow{2}{*}{ Treatment } & \multicolumn{5}{|c|}{ Aggregate size distribution (mm) } & \multirow{2}{*}{ WAS $(\%)$} \\
\cline { 2 - 6 } & $2 \sim 10$ & $1 \sim 2$ & $0.5 \sim 1$ & $0.25 \sim 0.5$ & $<0.25$ & \\
\hline Before freezing-thawing event & $19.61 \mathrm{a}$ & $14.21 \mathrm{~b}$ & $21.88 \mathrm{~b}$ & $18.75 \mathrm{a}$ & $25.55 \mathrm{a}$ & $74.45 \mathrm{~b}$ \\
\hline After freezing-thawing event & $18.61 \mathrm{~b}$ & $21.19 \mathrm{a}$ & $26.74 \mathrm{a}$ & $15.55 \mathrm{~b}$ & $17.91 \mathrm{~b}$ & $82.09 \mathrm{a}$ \\
\hline
\end{tabular}

Means in columns without common lower case letter (a-b) differ significantly at $\mathrm{P}<0.05$.

Table 5. Description of soil temperature break curves in pretest.

\begin{tabular}{|c|c|c|c|c|c|c|}
\hline \multirow{2}{*}{ Soil layer } & \multicolumn{5}{|c|}{ Duration time } \\
\cline { 2 - 7 } & $\begin{array}{c}\text { Room } \\
\text { temperature to } \\
\text { subzero } \\
\text { temperature }\end{array}$ & $\begin{array}{c}\text { Subzero } \\
\text { temperature to } \\
\text { minimum } \\
\text { temperature }\end{array}$ & $\begin{array}{c}\text { Relative } \\
\text { constant } \\
\text { temperature }\end{array}$ & $\begin{array}{c}\text { Minimum } \\
\text { temperature to } \\
\text { zero temperature }\end{array}$ & $\begin{array}{c}\text { Zero temperature } \\
\text { to maximum } \\
\text { temperature }\end{array}$ & $\begin{array}{c}\text { Relative } \\
\text { constant } \\
\text { temperature }\end{array}$ \\
\hline Surface & $3 \mathrm{~h}$ & $16 \mathrm{~h}$ & $5 \mathrm{~h}$ & $5 \mathrm{~h}$ & $28 \mathrm{~h}$ & $15 \mathrm{~h}$ \\
\hline $5 \mathrm{~cm}$ & $6 \mathrm{~h}$ & $14 \mathrm{~h}$ & $4 \mathrm{~h}$ & $10 \mathrm{~h}$ & $25 \mathrm{~h}$ & $13 \mathrm{~h}$ \\
\hline $10 \mathrm{~cm}$ & $6 \mathrm{~h}$ & $14 \mathrm{~h}$ & $4 \mathrm{~h}$ & $10 \mathrm{~h}$ & $25 \mathrm{~h}$ & $13 \mathrm{~h}$ \\
\hline $15 \mathrm{~cm}$ & $7 \mathrm{~h}$ & $13 \mathrm{~h}$ & $4 \mathrm{~h}$ & $12 \mathrm{~h}$ & $24 \mathrm{~h}$ & $12 \mathrm{~h}$ \\
\hline
\end{tabular}

In this study, results for WAS and aggregate size distribution after seasonal FT were similar to those observed in the VTR method and after 6 FT cycles in the RTCR method for 38\% water content (Fig. 5). These trends were associated with all settings for FT, i.e., cycle amplitude, freezing rate, number and frequency of FT cycles (Tables 3-4). A soil sample needed at least 7 hours to be completely frozen from room temperature $\left(20^{\circ} \mathrm{C}\right)$ to subzero temperature under setting temperature $\left(-15^{\circ} \mathrm{C}\right)$, and 12 hours to be completely thawed from minimum to zero temperature under setting temperature $\left(8^{\circ} \mathrm{C}\right)$ in a constant temperature chamber (Table 5). Based on Tables 5 and 6 , we found 22 FT cycles at the

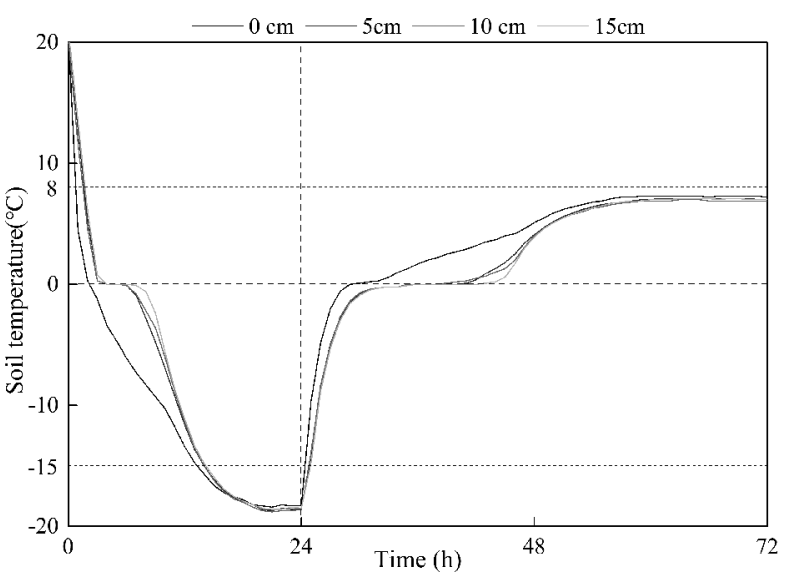

Fig. 6. Soil temperature break curves (soil surface, 5, 10 and 15 $\mathrm{cm}$ depth) for a northeastern China mollisol using the repeated temperature cycle regime (RTCR) treatment of soil aggregate stability. soil surface, only 5 of which extended through the entire soil sample with the VTR method. Therefore, the VTR method had a similar number of FT cycles with the field conditions, which helps explain why the results from the VTR method were similar to the result with 6 FT cycles in the RTCR method, while also better matching the results from the field. Table 6 also shows that the number of FT cycles decreased with increasing depth - as would be expected given how temperature change in soil is driven by atmospheric conditions. A critical observation for Fig. 1 was the difference in the number and duration of FT cycles in the upper and lower portions of the field soil, which indicates a need for laboratory methods that mimic this differential upper-lower cycling. Our data indicates that RTCR only replicated the deep soil conditions while VTR better replicated both.

Even though the VTR chamber matched real field temperatures, the result between VTR treatment and natural conditions was not completely consistent in the soil surface. We attribute this in part to the snow covers on the soil surface in the field, which alters how air temperature impacts soil temperature flux. Second, there were different moisture contents for soil samples in the chamber and natural conditions. This was intensified by the seasonal changes of the natural environment. In spite of these deficiencies, VTR met every criteria of the RTCR while better replicating shallow, medium and deep conditions of the field soil data. We recognize that this approach may not be perfect for mimicking field conditions, but it is designed to be one step closer to actually predicting spring stable aggregate content for Mollisols in cryic, frigid and cold mesic soil temperature regimes. 
Soil Aggregate Response to Three...

Table 6. Description of observed temperature in CTC and 4 soil layers in natural conditions.

\begin{tabular}{|c|c|c|c|c|c|c|c|c|c|c|}
\hline \multirow{4}{*}{ FTC } & \multicolumn{10}{|c|}{ Duration Time (h) } \\
\hline & \multirow{2}{*}{\multicolumn{2}{|c|}{ VTR chamber }} & \multicolumn{8}{|c|}{ Natural condition } \\
\hline & & & \multicolumn{2}{|c|}{ Soil surface } & \multicolumn{2}{|c|}{$5 \mathrm{~cm}$} & \multicolumn{2}{|c|}{$10 \mathrm{~cm}$} & \multicolumn{2}{|c|}{$15 \mathrm{~cm}$} \\
\hline & $\mathrm{F}$ & $\mathrm{T}$ & $\mathrm{F}$ & $\mathrm{T}$ & $\mathrm{F}$ & $\mathrm{T}$ & $\mathrm{F}$ & $\mathrm{T}$ & $\mathrm{F}$ & $\mathrm{T}$ \\
\hline 1 & 70 & 4 & 16 & 6 & 6 & 158 & 506 & 106 & 744 & 62 \\
\hline 2 & 232 & 2 & 16 & 8 & 14 & 12 & 6 & 12 & 14 & 12 \\
\hline 3 & 20 & 4 & 18 & 8 & 8 & 9 & 10 & 258 & 10 & 12 \\
\hline 4 & 382 & 6 & 6 & 20 & 656 & 86 & 12 & 6 & 178 & 218 \\
\hline 5 & 162 & 2 & 14 & 38 & 6 & 16 & 68 & 282 & & \\
\hline 6 & 22 & 4 & 10 & 6 & 8 & 258 & & & & \\
\hline 7 & 18 & 6 & 44 & 4 & 84 & 8 & & & & \\
\hline 8 & 68 & 4 & 18 & 8 & 12 & 88 & & & & \\
\hline 9 & 16 & 14 & 44 & 2 & 4 & 20 & & & & \\
\hline 10 & 8 & 40 & 20 & 4 & 4 & 172 & & & & \\
\hline 11 & 12 & 6 & 18 & 6 & & & & & & \\
\hline 12 & 18 & 32 & 18 & 8 & & & & & & \\
\hline 13 & 16 & 6 & 234 & 14 & & & & & & \\
\hline 14 & 16 & 10 & 128 & 10 & & & & & & \\
\hline 15 & 14 & 12 & 184 & 4 & & & & & & \\
\hline 16 & 12 & 6 & 18 & 8 & & & & & & \\
\hline 17 & 116 & 6 & 18 & 4 & & & & & & \\
\hline 18 & 16 & 8 & 18 & 6 & & & & & & \\
\hline 19 & 18 & 4 & 16 & 10 & & & & & & \\
\hline 20 & 42 & 8 & 14 & 10 & & & & & & \\
\hline 21 & 14 & 20 & 14 & 40 & & & & & & \\
\hline 22 & 4 & 148 & 6 & 14 & & & & & & \\
\hline 23 & & & 12 & 20 & & & & & & \\
\hline 24 & & & 2 & 16 & & & & & & \\
\hline 25 & & & 10 & 10 & & & & & & \\
\hline 26 & & & 14 & 10 & & & & & & \\
\hline 27 & & & 14 & 14 & & & & & & \\
\hline 28 & & & 10 & 10 & & & & & & \\
\hline 29 & & & 94 & 2 & & & & & & \\
\hline 30 & & & 14 & 10 & & & & & & \\
\hline 31 & & & 14 & 12 & & & & & & \\
\hline 32 & & & 12 & 10 & & & & & & \\
\hline 33 & & & 14 & 10 & & & & & & \\
\hline 34 & & & 14 & 10 & & & & & & \\
\hline 35 & & & 12 & 20 & & & & & & \\
\hline 36 & & & 4 & 18 & & & & & & \\
\hline 37 & & & 6 & 42 & & & & & & \\
\hline
\end{tabular}


Table 6. Continued.

\begin{tabular}{|l|l|l|l|l|l|l|l|l|l|l|}
\hline 38 & & & 6 & 14 & & & & & & \\
\hline 39 & & & 10 & 54 & & & & & & \\
\hline
\end{tabular}

F: Freezing process (duration time of subzero temperature), T: Thawing process (duration time of above zero temperature)

\section{Conclusions}

Our results show that freezing and thawing significantly $(\mathrm{P}<0.05)$ increased the WAS of all soils. The proportion of WAS decreased at first and then increased with the increasing FT cycles in the RTCR method, but the percentage of WAS in all samples decreased with the water content increasing after freezing and thawing in the RTCR and VTR methods.

The VTR method successfully simulated field conditions by using replicated large volumes of soil in insulated chambers with the overall chamber temperature fluxes being continuously recorded. This experimental set-up was successful in approximating actual field temperature fluxes. Furthermore, this setup closely mimics the effect of freezing and thawing on aggregate size distribution and WAS in field conditions. The VTR method was also easy to continue beyond a few cycles and had few unintended effects. These findings show that the VTR method has great potential in simulating FT cycles and will be a useful tool to further study in laboratory conditions.

\section{Abbreviations}

CTC, controlled tempresure chamber; FT, freezethaw; FTC, numbers of freeze-thaw cycles; FTT, freezethaw treatments; nHVSW, new high vacuum slow wetting; RTCR, repeated temperature cycle regime; VTR, variable temperature regime; W, water contents; WAS, wet aggregate stability.

\section{Acknowledgements}

This study was supported by a project of the National Science Foundation of China (No. 41571264) and data support from the Scientific Data Center of Northeast Black Soil, National Earth System Science Data Sharing Infrastructure, National Science and Technology Infrastructure of China (http://northeast.geodata.cn). The authors also acknowledge financial support from a program of the China Scholarship Council.

\section{Conflict of Interest}

The authors declare no conflict of interest.

\section{References}

1. JABRO J., IVERSEN W., EVANS R., ALLEN B., STEVENS W. Repeated freeze-thaw cycle effects on soil compaction in a clay loam in northeastern Montana. Soil Sci. Soc. Am. J. 78 (3), 737, 2014.

2. WERTZ S., GOYER C., ZEBARTH B.J., TATTI E., BURTON D.L., CHANTIGNY M.H., FILION M. The amplitude of soil freeze-thaw cycles influences temporal dynamics of $\mathrm{N} 2 \mathrm{O}$ emissions and denitrifier transcriptional activity and community composition. Biol. Fertil. Soils, $\mathbf{5 2}$ (8), 1149, 2016.

3. ABD-ELSALAM K.A., BAHKALI A.H., MOSLEM M.A., AL-HAZZANI A.A., AMIN O.E., AL-KHEDHAIRY A. Freeze and thaw based procedures for extracting DNA from activated sludge. Polish. J. Environ. Studies, 20 (3), 643, 2011.

4. YU X., ZOU Y., JIANG M., LU X., WANG G., Response of soil constituents to freeze-thaw cycles in wetland soil solution. Soil Biol. Biochem. 43 (6), 1308, 2011.

5. GUO D., YANG M., WANG H. Characteristics of land surface heat and water exchange under different soil freeze/thaw conditions over the central Tibetan Plateau. Hydrol. Processes, 25 (16), 2531, 2011.

6. SAWICKA J.E., ROBADOR A., HUBERT C., J RGENSEN B.B., BR CHERT V., Effects of freeze-thaw cycles on anaerobic microbial processes in an Arctic intertidal mud flat. ISME J. 4 (4), 585, 2010.

7. HENRY H.A. Soil freeze-thaw cycle experiments: trends, methodological weaknesses and suggested improvements. Soil Biol. Biochem. 39 (5), 977, 2007.

8. FOULI Y., CADE-MENUN B.J., CUTFORTH H.W. Freeze-thaw cycles and soil water content effects on infiltration rate of three Saskatchewan soils. Can. J. Soil Sci. 93 (4), 485, 2013.

9. WANG E., CRUSE R.M., CHEN X., DAIGH A. Effects of moisture condition and freeze/thaw cycles on surface soil aggregate size distribution and stability. Can. J. Soil Sci. 92 (3), 529, 2012.

10. EDWARDS L.M. The effects of soil freeze-thaw on soil aggregate breakdown and concomitant sediment flow in Prince Edward Island: A review. Can. J. Soil Sci. 93 (4), 459, 2013.

11. LEHRSCH G.A. Freeze-thaw cycles increase near-surface aggregate stability. Soil Sci. 163 (1), 63, 1998.

12. POLAT R., DEMIRBOĞA R., KARAKO M.B., TRKMEN İ. The influence of lightweight aggregate on the physicomechanical properties of concrete exposed to freeze-thaw cycles. Cold Reg. Sci. Technol. 60 (1), 51, 2010.

13. SAHIN U., ANGIN I., KIZILOGLU F.M. Effect of freezing and thawing processes on some physical properties of saline-sodic soils mixed with sewage sludge or fly ash. Soil Tillage Res. 99 (2), 254, 2008.

14. LI G.Y., FAN H.M. Effect of freeze-thaw on water stability of aggregates in a black soil of Northeast China. Pedosphere, 24 (2), 285, 2014. 
15. KVÆRNØ S.H., ØYGARDEN L. The influence of freezethaw cycles and soil moisture on aggregate stability of three soils in Norway. Catena, 67 (3), 175, 2006.

16. LIPSON D.A., MONSON R.K. Plant-microbe competition for soil amino acids in the alpine tundra: effects of freezethaw and dry-rewet events. Oecologia, 113 (3), 406, 1998.

17. LIPSON D.A., SCHMIDT S.K. Seasonal changes in an alpine soil bacterial community in the Colorado Rocky Mountains. Appl. Environ. Microbiol. 70 (5), 2867, 2004.

18. CHEN Y., LIU S., LI H., LI X.F., SONG C.Y., CRUSE R.M., ZHANG X.Y. Effects of conservation tillage on corn and soybean yield in the humid continental climate region of Northeast China. Soil Tillage Res. 115, 56, 2011.

19. LIU S., YANG J.Y., ZHANG X.Y., DRURY C.F., REYNOLDS W.D., HOOGENBOOM G. Modelling crop yield, soil water content and soil temperature for a soybeanmaize rotation under conventional and conservation tillage systems in Northeast China. Agric. Water Manage. 123, 32, 2013.

20. SUN T., CHEN Q., CHEN Y., CRUSE R.M., LI X.F., SONG C.Y., KRAVCHENKO Y.S., ZHANG X.Y. A novel soil wetting technique for measuring wet stable aggregates. Soil Tillage Res. 141, 19, 2014.

21. SUN F., LU S. Biochars improve aggregate stability, water retention, and pore-space properties of clayey soil. J. Plant Nutr. Soil Sci. 177 (1), 26, 2014.

22. DENEF K., SIX J., PAUSTIAN K., MERCKX R. Importance of macroaggregate dynamics in controlling soil carbon stabilization: short-term effects of physical disturbance induced by dry-wet cycles. Soil Biol. Biochem. 33 (15), 2145, 2001.

23. ANNABI M., LE BISSONNAIS Y., LE VILLIOPOITRENAUD M., HOUOT, S. Improvement of soil aggregate stability by repeated applications of organic amendments to a cultivated silty loam soil. Agric. Ecosyst. Environ. 144 (1), 382, 2011.

24. VERMANG J., DEMEYER V., CORNELIS W., GABRIELS D. Aggregate stability and erosion response to antecedent water content of a loess soil. Soil Sci. Soc. Am. J. 73 (3), 718, 2009.
25. NAVARRO-GARC A F., CASERMEIRO M.Á., SCHIMEL J.P. When structure means conservation: effect of aggregate structure in controlling microbial responses to rewetting events. Soil Biol. Biochem. 44 (1), $1,2012$.

26. B NEMANN E., KELLER B., HOOP D., JUD K., BOIVIN P., FROSSARD E. Increased availability of phosphorus after drying and rewetting of a grassland soil: processes and plant use. Plant Soil, 370 (1-2), 511, 2013.

27. SHI A., MARSCHNER P. Drying and rewetting frequency influences cumulative respiration and its distribution over time in two soils with contrasting management. Soil Biol. Biochem. 72, 172, 2014.

28. MARQUEZ C., GARCIA V., CAMBARDELLA C.A., SCHULTZ R.C., ISENHART T.M. Aggregate-size stability distribution and soil stability. Soil Sci. Soc. Am. J. 68 (3), 725, 2004.

29. BRONICK C.J., LAL R. Soil structure and management: a review. Geoderma, 124 (1-2), 3, 2005.

30. CHONG-FENG B., GALE W., QIANG-GUO C., SHUFANG W. Process and mechanism for the development of physical crusts in three typical Chinese soils. Pedosphere, 23 (3), 321, 2013.

31. LIU H., LEI T., ZHAO J., YUAN C., FAN Y., QU L. Effects of rainfall intensity and antecedent soil water content on soil infiltrability under rainfall conditions using the run off-on-out method. J. Hydrol. 396 (1-2), 24, 2011.

32. LEHRSCH G., SOJKA R., CARTER D., JOLLEY P. Freezing effects on aggregate stability affected by texture, mineralogy, and organic matter. Soil Sci. Soc. Am. J. 55 (5), 1401, 1991.

33. KREYLING J., BEIERKUHNLEIN C., JENTSCH A. Effects of soil freeze-thaw cycles differ between experimental plant communities. Basic Appl. Ecol. 11 (1), 65, 2010.

34. OZTAS T., FAYETORBAY F. Effect of freezing and thawing processes on soil aggregate stability. Catena, $\mathbf{5 2}$ (1), 1, 2003. 